\title{
Literacy development of English language learners: The outcomes of an intervention programme in grade $R$
}

\author{
Anna-Mari Olivier \\ Christine Anthonissen \\ Frenette Southwood \\ Department of General Linguistics, Stellenbosch University, W Cape
}

Correspondence to: A-M Olivier (annamari@iafrica.com)

\begin{abstract}
This study aims to contribute to the knowledge base on the status and development of emergent literacy skills of learners receiving formal education in their second or additional language. The focus is on young English language learners (ELLs), i.e. learners whose home language is not English but who have English as their language of teaching and learning. This article reports on a study that investigated ELLs' emergent literacy skills prior to entering grade 1 and then evaluated the effectiveness of an evidence-based stimulation programme on early literacy skills in the South African context. Using a quasi-experimental design, ELLs' emergent literacy skills were assessed with an adapted version of 8 of the subtests of the Emergent Literacy Assessment battery (Willenberg, 2004) and were compared to those of English first language (L1) and of ELL control groups, both before and after the 8-week purpose-designed programme. While learners showed significant improvement on 6 of the 8 subtests, the programme did not significantly improve ELLs' skills in comparison to those of the control groups. Possible independent variables contributing to the dearth of intervention effect include socio-economic status, learners' L1, and teacher- and classroom-specific characteristics, all of which were considered in this study. Clinical implications for speech-language therapists with regard to assessment, intervention, service delivery and outcome measures are highlighted.
\end{abstract}

Keywords: emergent literacy, English language learners, language stimulation programme, preschoolers, second-language learners

Identifying children at risk of developing reading difficulties and providing timely and preventive intervention are starting points to addressing the challenge of low literacy rates in South Africa. Justice (2006a) proposes that many children do not exhibit basic reading proficiency at the expected stage of their development because schools fail to provide adequate educational support for children with certain characteristics which place them at risk of developing reading difficulties. Several such risk factors, which leave preschoolers vulnerable to experiencing difficulties in acquiring critical emergent literacy skills, have been identified in the literature and include factors inherent to the child - e.g. language, cognitive and/or hearing impairment; attention deficits; a family history of reading difficulty; and/or low educational attainment of the mother - as well as factors pertaining to the environment, e.g. low socio-economic status (SES) and/or a first language that varies dialectally from that of the local academic curriculum (Catts, Fey, Zhang \& Tomblin, 2001; Cavanaugh, Kim, Wanzek \& Vaughn, 2004; Duncan \& Seymour, 2000). According to McGee and Richgels (2003), the combination of limited proficiency in the language of education, minority status and a low SES is the best predictor that a child will fail to learn to read and write well.

In South Africa, monolingualism is the exception rather than the norm. This poses several challenges to parents and teachers in selecting and using a language of teaching and learning in educational programmes. In the Western Cape, where isiXhosa, English and Afrikaans are the three languages used as first languages (L1s) by the overwhelming majority of residents, the Language Policy of Primary Schools of November 2002 (Western Cape Education Department, 2002) contained two central recommendations: $(i)$ to implement a policy of mother-tongue-based bilingual education in grades $\mathrm{R}$ to 6 from $2004 / 2005$ in all primary schools in the province; and (ii) to institute incentives to guide all children towards electing to take the third official language of the province as their second additional language. Parents have been encouraged by means of information brochures and media awareness programmes to enrol their children in mothertongue education; however, statistics from the Western Cape Education

${ }^{\star}$ For the purposes of this article, the term English language learners (ELLs) will be used for such learners, i.e. for learners who are educated through the medium of English, but who have an L1 other than English.
Department (WCED) (personal communication, 2005) indicate that $25.7 \%$ of the learners attending English-medium primary schools in the Western Cape did not have English as their home language. ${ }^{*}$ In the Southern Cape and Karoo region of the Western Cape, where the present study was conducted, on average 20\% of learners in Englishmedium classrooms came from homes in which English is not the primary language spoken, and in some classrooms this figure rises to 92.3\% (WCED, personal communication, 2007).

Therefore, despite recommendations and efforts from the WCED to promote mother-tongue education, parents choose to enrol their children at primary schools where English is the language of teaching and learning. This choice is related to the trend among non-Englishspeaking South Africans to raise their children as L1 English speakers (Anthonissen, 2009; Willenberg, 2004), as English is still widely regarded as the language of prestige and opportunity.

Limited proficiency in the language of education has been identified as a possible risk factor for literacy development difficulties; however, studies that have investigated the influence of oral language proficiency and early literacy knowledge so far have focused mainly on children with specific language impairment (SLI) and children with phonological disorders (Bird, Bishop \& Freeman, 1995; Boudreau \& Hedberg, 1999). Very few studies have investigated the prevalence and literacy development of ELLs with reading disabilities (Lipka \& Siegel, 2007). While there is wide variation in the effectiveness of educational programmes, it is known that minority language learners are at a higher than average risk for failure or difficulty in second language (L2)-only classrooms (Genesee, Paradis \& Crago, 2004). These learners face several challenges, such as acquiring a new language, integrating socially into a new peer group and learning new academic skills and knowledge, often doing so without the support of an educator who is proficient in their L1. On their own each of these factors could inhibit literacy development, with compounded risk when they have to be dealt with simultaneously.

The cohort of L2 learners in English submersion educational programmes is indeed a highly heterogeneous group. Not only do they enter formal schooling with different L1s and different levels of proficiency in their L1 and their L2, but there are several other factors 
that can also influence L2 acquisition, and consequently the child's overall language proficiency. These factors include the timing of L2 acquisition (i.e. simultaneous v. sequential acquisition), the environment in which the L2 is/was acquired and the degree to which the home language is/was maintained, as well as innate characteristics such as personality, motivation and language aptitude (Moore, Pérez-Méndez \& Boerger, 2006).

Environmental factors pertaining to the home environment further contribute to the heterogeneity within the ELL population. Parents' level of proficiency in the child's language of education, their interactive strategies, and their beliefs regarding and values attached to literacy and personal characteristics such as their psychological well-being have all been shown to have an effect on the quality of the home literacy environment (Bennett-Armistead, Duke \& Moses, 2005; Willenberg, 2004). In addition to the learner's home environment, the quality of literacy exposure and instruction in the preschool classroom contributes to the heterogeneity of the ELL population entering primary school (Morrow, 2007). As many educators lack knowledge regarding the promotion and facilitation of ELLs' oral language skills, the quality of conversational exchanges and literacy-related experiences in preschool settings are highly variable (Dickinson \& Tabors, 2001, as cited in Justice 2006a).

A final factor contributing to the heterogeneity of the ELL population in the South African context involves the variability of L1s spoken in any particular classroom. Data from the WCED (personal communication, 2005) indicated that the majority of learners attending English-medium primary schools in the Western Cape spoke either English, isiXhosa, Afrikaans or isiZulu as home language, but that it is not unusual to come across L1 speakers of any of the seven other official languages, or unofficial languages, in these classrooms. While multilingual children are often credited with more advanced metalinguistic awareness than their monolingual peers (Bialystok, 2001; Genesee et al., 2004), teachers' limited proficiency in the ELLs' L1 and the limited availability of teaching assistants in L2-only classrooms may confine the potential advantages on which ELLs should in theory be able to capitalise.

While learners educated in their L2 are identified as particularly vulnerable to reading difficulties, it is also widely acknowledged that an intervention programme should intervene at an appropriate level and should target identified and measurable areas of strengths and weaknesses. This study aimed to prevent literacy difficulties in a highrisk population and not to provide remedial therapy for diagnosed reading disorders. However, a precise understanding of a learner's current level of language and literacy proficiency is essential for providing individual and personalised support for at-risk ELLs (McGee \& Richgels, 2003). Assessment of ELLs is a particularly contentious topic for SLTs and educationalists in South Africa, as double jeopardy is always a possibility: we are assessing young learners with limited exposure to formal test situations who might be unfamiliar with task requirements, and we are often assessing children with limited exposure to the medium of print. The lack of appropriate assessment materials as well as the lack of normative data on typical bilingual development or early sequential bilingual development should also be borne in mind when assessing ELLs and drawing conclusions regarding their language abilities. In order to take into account the specific needs of the ELL population, a dynamic assessment approach which includes both formal and more client-centred tasks is proposed (Paul, 2007). By using different tasks (e.g. formal picture selection procedures as well as spontaneous language sampling), quantitative as well as qualitative information is gathered, and by supplementing formal test measures with dynamic and informal measures, the examiner can also adapt the protocol depending on the child's familiarity with the task and the test environment, and can take aspects such as code switching into consideration when analysing and interpreting the child's performance (Müller, 2003).

According to Justice (2006a), the most desirable emergent literacy areas to assess are those that: $(i)$ directly contribute to and are predictive of later reading and writing achievements; and (ii) are amenable to change through intervention. In a meta-analysis conducted by the National Early Literacy Panel (2004, cited in Justice, 2006a), the following areas were found to consistently and most strongly relate to later reading achievement: (i) alphabet knowledge - i.e. receptive or expressive knowledge of the individual letters of the alphabet as well as phoneme-grapheme awareness (Nancollis, Lawrie \& Dodd, 2005); (ii) concepts about print - i.e. knowledge of the rules governing how print is used across various genres, e.g. books or environmental print; (iii) phonological awareness - i.e. sensitivity to the sound structure of spoken language, in particular on phoneme level; (iv) invented spelling - i.e. representation of the orthography of written language; $(v)$ oral language - this includes syntactic, lexical and narrative abilities; and (vi) name writing.

The Emergent Literacy Assessment (ELA; Willenberg, 2004) is a comprehensive assessment battery that provides information on both conceptual and procedural emergent literacy skills. This assessment instrument was compiled by a South African researcher and used in her study with 101 grade $\mathrm{R}$ learners from historically disadvantaged communities in the Western Cape. Use of the ELA provided the opportunity to compare and contrast results with those of the comprehensive Willenberg study; however certain changes were made to the original ELA for the purposes of the present study based on the following limitations that were identified:

1. The small number of test items in some subtests heightened the possibility of chance responses, and extra items were therefore added.

2. In the original five items in the sound-in-word final test, onset-rime combinations were utilised, e.g. fan-bat-cat. Phoneme segmentation proved to be a particularly consistent predictor of reading ability (Hulme, Hatcher, Nation, Brown, Adams \& Stuart, 2002), and therefore five additional items were selected which required learners to isolate only the final phoneme, e.g. mop-tap-pen.

3.The inclusion of rhyming tasks in the assessment battery (and by implication also the predictive value in terms of later reading success) is a contentious issue in the literature. Bradley and Bryant (1983) argued that large phonological units (e.g. rhyming) have definite predictive value, while Goswami and Bryant (1990) confirmed that children normally progress from an awareness of syllables via onsetrime to phonemes, indicating a normal developmental pattern with prognostic value. Goswami and Bryant (1990) suggested that onset and rhyme sensitivity make a direct and specific contribution to word reading ability. While the jury is still out on this aspect, the two rhyming subtests of the ELA were retained for the purpose of this study, for the following reasons: $(i)$ a strong predictive relation between onset-rime awareness and reading development has been shown for English, the medium of assessment in the current study; and (ii) in view of the small body of research in the area of emergent literacy in South Africa, and consequently the dearth of normative data, the Willenberg (2004) study provided valuable comparative data for the current study. Inclusion of these two subtests provided the researchers with more data regarding emergent literacy performance of South African preschoolers.

4. A fourth limitation of the ELA battery is its exclusively linguistic perspective, primarily concerned with the description of different language-related behaviours. Although the subtests suffice in identifying and describing areas of difficulty, no account is taken of underlying cognitive processes that might shed more light on the nature of the difficulties (Stackhouse \& Wells, 1997). As no theoretical model of speech processing underpinned the compilation of the ELA, no hypothesis can be generated about the level of breakdown that gives rise to specific literacy difficulties. A psycholinguistic approach in assessment of literacy development of ELLs might be particularly useful at the second and third tiers of assessment, when differential diagnosis of ELLs with literacy disorders becomes an important aim. 
5. Finally, while it is the authors' belief that ELLs should be assessed in all their respective languages before any diagnoses regarding language delays or language impairments are made, the aim of assessment in the current study was not differential diagnosis of reading difficulties, but a discrete-point comparison of preschoolers' emergent literacy abilities in order to monitor their progress during the first tier of literacy intervention (Justice, 2006b). While the research was conducted in submersion classrooms where the ELLs' L1 was not utilised in acquiring literacy skills, the ELA battery was only conducted in English and not translated into any of the home languages of the ELLs concerned.

Several studies have indicated that sustained and intensive preventive interventions from preschool through to grade 2 are effective in reducing reading difficulties among at-risk learners (Justice, 2006b; Vaughn, Linan-Thompson \& Hickman, 2003). Having reviewed the literature with regard to intervention studies for preschool ELLs, we synthesised findings to set up a framework for the delivery of emergent literacy intervention in the South African context. Kaderavek and Justice (2004) suggest an integrated approach to intervention. The authors distinguish two approaches to emergent literacy intervention: a 'top-down' holistic model and 'bottom-up' reductionist learning model. The holistic model emphasises whole-language principles through child-directed, informal and naturalistic interactions, while the 'bottom-up' model emphasises explicit and directive teaching of critical literacy concepts. Examples of embedded holistic intervention strategies would include literacyenriched play settings, print-rich classroom environments and adultchild shared storybook reading (Morrow, 2007; Whitehurst \& Lonigan, 2002). Examples of more explicit, structured and teacher- or cliniciandirected approaches would involve intervention programmes that provide deliberate, scaffolded exposure to specific concepts and skills, e.g. phonological awareness, concepts of print and alphabet knowledge. Kaderavek and Justice (2004) propose an embedded-explicit model which synthesises two strands of evidence-based practices, i.e. holistic intervention through daily embedded opportunities by the SLT in consultation and collaboration with the teacher and direct and explicit intervention of specific concepts and skills by the SLT.

In an attempt to develop such an embedded-explicit intervention programme for preschool ELLs in the South-African context, a pilot study was conducted in the Southern Cape and Karoo region (cf. Olivier, 2009). Thirty-two grade R learners were assessed on 10 subtests of the ELA battery (Willenberg, 2004), and their performance was analysed by taking six independent variables into account. The learners' age, gender and school and mothers' level of education did not have any significant influence on their performance. However, those with a higher SES performed better on oral language-related subtests, and English L1 learners performed significantly better than their ELL peers on 8 of the 10 subtests. Based on these results as well as evidence-based recommendations in the literature, a stimulation programme (the bridging programme for ELLs to accelerate reading development skills (BEARS programme) was compiled to be implemented and evaluated in this study. Acquiring literacy poses unique challenges in a context where learning takes place through medium of an L2, and our hypothesis was that a well-developed and comprehensive stimulation programme would have statistically significant benefits for the L2 learner.

\section{Method}

The main research question was: 'What is the effect of a particular emergent literacy stimulation programme in grade $\mathrm{R}$ on the development of literacy of ELLs in grade 1?' In order to answer this question comprehensively, the study had the following specific aims:

1. To ascertain the emergent literacy skills of English L1 learners and ELLs in grade R, 4 months before entering grade 1.

2. After administering the developed programme to a selected group of ELLs, to determine the measurable effects on emergent literacy skills that are registered upon entering grade 1.

3. To establish whether independent variables such as SES, home language and school environment have an effect on performance on the eight subtests of the ELA battery administered in this study.

\section{Research design}

A quasi-experimental design compared four groups of participants with repeated measures, assessing performance on eight different emergent literacy subskills. Two experimental groups and two control groups took part in this study. Two subtests of the ELA, namely emergent writing and spelling and environmental print, were not included in this study, as ELLs in the pilot study performed similarly to their English L1 peers on these subtests. These two subskills can therefore be regarded as areas of strength for ELLs. The subskills assessed by the remaining eight ELA subtests are those in which the pilot study indicated notable differences between ELLs and English L1 learners; these were therefore regarded as priority areas of development to be included in the stimulation programme. A pre- and post-measurement intervention design was used, and results were analysed both quantitatively and qualitatively.

\section{Participants}

Based on feedback from principals regarding the language profiles in grade R classrooms, as well as their agreement to allow their learners to participate in the study, four primary schools in the Eden and Central Karoo district were selected for inclusion in this study. Permission was then obtained from the WCED to conduct the main study in these four schools. Table I outlines the profiles of the participating schools.

Participants all attended grade $\mathrm{R}$ classes in the four participating schools. Two control classrooms (teachers $b$ and $d$ ) and three experimental classrooms (teachers a, $\mathrm{c}$ and e) were selected within the four participating schools. Within these five classrooms, participants were randomly selected from class lists and assigned to one of four groups (Table II), based on their home language. In order to control for teacher-specific qualities, the four groups were each made up of learners from at least two different classrooms (except for group 2, one of the control groups, which had learners in school C only).

As the stimulation programme was developmental in nature and targeted ELLs who were considered at risk for literacy difficulties, no attempt was made to distinguish and exclude learners with possible language disorders, in order to create a true representation of the general grade $\mathrm{R}$ population.

Seventy-two participants were assigned to the four research groups and were assessed pre-intervention. Six participants left the study, as their

\section{Table I. Profiles of participating schools}

\begin{tabular}{|c|c|c|c|c|}
\hline School & Medium of instruction & WCED poverty index ${ }^{\star}$ & Total number of learners & Number of learners/ grade R classroom \\
\hline School A & English-Afrikaans parallel medium & 5 & 342 & 26 \\
\hline School B & English medium & 5 & 598 & 27 \\
\hline School C & English-Afrikaans parallel medium & 5 & 203 & 27 \\
\hline School D & English-Afrikaans parallel medium & 5 & 409 & 23 \\
\hline
\end{tabular}


Table II. Allocation of participants to groups

\begin{tabular}{|c|c|c|c|c|c|}
\hline $\begin{array}{l}\text { Group } \\
1\end{array}$ & $\begin{array}{l}\text { Description } \\
\text { English L1 learners } \\
\text { No additional intervention }\end{array}$ & $\begin{array}{l}\text { School } \\
\text { School B } \\
\text { School C }\end{array}$ & $\begin{array}{l}\text { Teacher } \\
\text { B } \\
\text { D }\end{array}$ & $\begin{array}{r}n \\
13 \\
3\end{array}$ & Total $N$ \\
\hline 2 & $\begin{array}{l}\text { English L2 learners } \\
\text { No additional intervention }\end{array}$ & School C & $\mathrm{D}$ & 10 & 10 \\
\hline 3 & $\begin{array}{l}\text { English L2 learners } \\
\text { Language-focused stimulation }\end{array}$ & $\begin{array}{l}\text { School A } \\
\text { School B }\end{array}$ & $\begin{array}{l}\mathrm{A} \\
\mathrm{C}\end{array}$ & $\begin{array}{r}10 \\
6\end{array}$ & 16 \\
\hline 4 & $\begin{array}{l}\text { English L2 learners } \\
\text { Comprehensive stimulation }\end{array}$ & $\begin{array}{l}\text { School B } \\
\text { School D }\end{array}$ & $\begin{array}{l}\mathrm{C} \\
\mathrm{E}\end{array}$ & $\begin{array}{r}9 \\
15\end{array}$ & 24 \\
\hline
\end{tabular}

families moved out of the area during the course of the study, and they subsequently attended grade 1 outside of the Eden and Central Karoo district.

All participants attended schools classified on the fifth quintile of the poverty index used by the WCED, indicating relatively similar socioeconomic environments. In order to better discriminate between participants in terms of their SES, an adapted version of the socioeconomic deprivation questionnaire (Du Plessis, 2003) was used to determine the SES of each participant. Based on parental responses to 6 questions, participants were assigned to one of two categories of SES: either low $(n=14)$ or high $(n=52)$. The finding that a small number of learners fell into the low SES category concurred with the fact that the four schools were all on the fifth quintile of the WCED's poverty index. Sixteen participants with English as their home language were assigned to one control group (group 1 - no additional stimulation programme provided). Fifty learners who did not have English as their home language, but did have it as their language of teaching and learning, were assigned to the three remaining groups: group 2 (control group receiving no additional stimulation programme); group 3 (experimental group receiving the first section of the stimulation programme, focusing exclusively on the development of oral language and conceptual knowledge); and group 4 (experimental group receiving the complete stimulation programme, focusing on oral language development as well as the stimulation of conceptual and procedural literacy skills and knowledge). These 50 learners had mostly either isiXhosa $(n=19)$ or Afrikaans $(n=25)$ as their home language, which is representative of the demographics of the Western Cape. Six participants had alternative home languages less well represented in this region, namely isiZulu $(n=2)$, Sesotho $(n=3)$ and Flemish $(n=1)$.

\section{Ethical considerations}

The study was approved by the WCED, and participating principals gave permission for the study to be conducted in the respective schools. Written consent was obtained from parents or guardians of all participants. Parents were informed that they could terminate their child's participation in the study at any time, without having to provide reasons for their decision. Participants and schools were given code names to ensure anonymity. Principals and teachers were contacted four times during the course of the study, to ensure understanding and to facilitate active participation. Upon completion of the study, the four participating schools were provided with a copy of the revised stimulation programme and results of this study were communicated to the participating schools and to the WCED.

\section{Data collection procedures}

The data collection stage of the main study consisted of four phases which took place over a period of 4 months, although not consecutively: (i) orientation of all participating teachers and training of teachers in the experimental classrooms; (ii) assessment of all participants prior to the implementation of the stimulation programme; (iii) implementation of the stimulation programme in the experimental classrooms; and (iv) assessment of all participants upon entering grade 1 .

Each participant was assessed on eight subtests of the adapted ELA (Willenberg, 2004). The content and scoring procedures of the ELA subtests used in this study are presented in Appendix A.

\section{Data analysis procedures}

In accordance with Willenberg's (2004) study, a binary scoring system ( 1 = correct; $0=$ incorrect) was utilised for 6 of the 8 subtests (refer to Appendix A). Qualitative rubrics were used to analyse responses on the remaining 2 subtests, namely word definition and fictional narrative. To limit researcher bias, these predesigned rubrics were used and, in order to control for inter-rater reliability for these 2 subtests, an agreement and consistency analysis was completed (StatSoft Inc., 2007). Specifically, an intra-class correlation (ICC) with a confidence interval was calculated to control for agreement and for consistency among raters. Reliability of the data collection procedures was established by using experienced SLTs who were not involved in the intervention process and who were blind to the allocation of participants to the respective groups.

In order to answer the respective research questions, the following statistical analyses were done:

Aim 1: Participant characteristics, mean scores, standard deviations and analysis of variance (ANOVA) were calculated and graphically represented, using the SPSS statistical software package (Version 15; Microsoft 2007).

Aim 2: Pre- and post-intervention data were analysed using repeated measures ANOVAs in order to determine any significant differences in scores for the main effects (namely time and intervention) as well as any interaction between the two main effects (time*intervention). Where statistically significant differences were measured, appropriate posthoc tests were performed. ANOVAs were calculated and graphically represented utilising both the StatSoft and SPSS software packages. Eight participants from each ELL group were matched according to their performance on the Peabody picture vocabulary test III (PPVTIIIB; Dunn \& Dunn, 1997), and the scores of these 24 participants were analysed with the ANOVA procedure to determine any significant differences in scores on the ELA battery.

Aim 3: Repeated measures ANOVAs were performed to determine whether SES, home language or school environment had any significant effect on participants' performance on the eight ELA subtests. In addition, qualitative feedback was obtained from the three teachers in the experimental classrooms to inform any necessary changes to the BEARS programme. A questionnaire and feedback form were completed anonymously and consisted of both closed and open-ended questions.

\section{Results and discussion}

Table III presents data on the performance of the four intervention groups on the eight subtests of the ELA during the last term of grade $\mathrm{R}$ and before implementation of the intervention programme for the two experimental groups.

ANOVA indicated no significant difference in mean scores on the subtests sounds-in-words, rhyme recognition, letter recognition and concepts of print, indicating that L1 learners did not perform significantly better than their L2 peers with regard to these emergent literacy subskills.

L1 learners (group 1) did not perform better than group 2, the ELL control group (to be discussed below). However, the L1 learners did 
Table III. Pre-intervention mean scores (M) and standard deviations (SDs), 4 months prior to entering grade 1

\begin{tabular}{|c|c|c|c|c|c|c|c|c|c|c|}
\hline \multirow[t]{2}{*}{ ELA subtest } & \multicolumn{2}{|c|}{ All participants $(n=66)$} & \multicolumn{2}{|c|}{ Group $1^{*}(n=16)$} & \multicolumn{2}{|c|}{ Group $2^{\dagger}(n=10)$} & \multicolumn{2}{|c|}{ Group $3^{*}(n=16)$} & \multicolumn{2}{|c|}{ Group $4^{\S}(n=24)$} \\
\hline & $\overline{\mathbf{M}}$ & SD & $\overline{\mathbf{M}}$ & SD & $\overline{\mathbf{M}}$ & SD & $\overline{\mathbf{M}}$ & SD & $\mathbf{M}$ & $\overrightarrow{\text { SD }}$ \\
\hline Sounds-in-words & 9.6 & 4.2 & 10.7 & 3.9 & 10.7 & 5.8 & 8.4 & 2.6 & 8.5 & 4.5 \\
\hline Rhyme recognition & 8.7 & 3.6 & 9.2 & 2.3 & 9.6 & 4.4 & 8.1 & 3.1 & 7.8 & 4.2 \\
\hline Rhyme production & 2.6 & 3.3 & 1.3 & 2.9 & 6.2 & 3.5 & 1.0 & 1.9 & 1.9 & 3.1 \\
\hline Letter recognition & 8.3 & 7.4 & 11.1 & 7.0 & 9.1 & 8.5 & 8.3 & 7.5 & 6.1 & 7.0 \\
\hline Concepts of print & 5.4 & 1.9 & 6.0 & 1.7 & 5.5 & 1.8 & 5.4 & 2.1 & 4.6 & 1.7 \\
\hline Word definitions & 31.2 & 15.1 & 36.4 & 10.2 & 44.6 & 18.4 & 26.0 & 11.6 & 18.0 & 8.8 \\
\hline Narrative ability & 6.0 & 3.3 & 8.2 & 2.4 & 6.8 & 3.5 & 5.1 & 3.6 & 4.0 & 2.2 \\
\hline PPVT-IIIB & 83.2 & 14.5 & 94.3 & 11.9 & 89.8 & 5.3 & 77.9 & 12.6 & 70.7 & 10.6 \\
\hline
\end{tabular}

"English L1 learners - no additional intervention.

${ }^{\dagger}$ ELLs - no additional intervention.

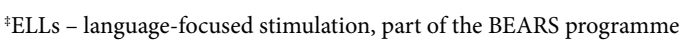

${ }^{5}$ ELLs - comprehensive literacy stimulation (i.e. complete BEARS programme).

Table IV. Mean scores (M) and standard deviations (SDs) upon entering grade 1, post intervention

\begin{tabular}{|c|c|c|c|c|c|c|c|c|c|c|}
\hline \multirow[t]{2}{*}{ ELA subtest } & \multicolumn{2}{|c|}{ All participants $(n=66)$} & \multicolumn{2}{|c|}{ Group $1^{*}(n=16)$} & \multicolumn{2}{|c|}{ Group $2^{\dagger}(n=10)$} & \multicolumn{2}{|c|}{ Group $3^{*}(n=16)$} & \multicolumn{2}{|c|}{ Group $4^{\S}(n=24)$} \\
\hline & $\bar{M}$ & SD & $\overline{\mathbf{M}}$ & $\overline{\text { SD }}$ & $\overline{\mathbf{M}}$ & SD & $\overline{\mathbf{M}}$ & $\overline{\text { SD }}$ & $\overline{\mathbf{M}}$ & SD \\
\hline Sounds-in-words & 12.3 & 3.8 & 13.9 & 3.2 & 13.9 & 4.5 & 10.3 & 3.3 & 11.0 & 3.4 \\
\hline Rhyme recognition & 9.9 & 3.0 & 10.3 & 2.5 & 12.2 & 2.9 & 8.4 & 2.5 & 8.6 & 3.0 \\
\hline Rhyme production & 4.2 & 3.7 & 4.2 & 3.3 & 7.3 & 3.7 & 2.1 & 2.9 & 3.2 & 3.7 \\
\hline Letter recognition & 12.1 & 8.0 & 15.3 & 6.7 & 18.8 & 7.5 & 9.0 & 7.0 & 9.2 & 7.4 \\
\hline Concepts of print & 5.7 & 1.6 & 6.3 & 1.5 & 6.4 & 0.8 & 5.4 & 1.7 & 4.8 & 1.4 \\
\hline Word definitions & 35.8 & 15.1 & 44.3 & 9.8 & 44.2 & 15.6 & 30.8 & 13.8 & 24.0 & 11.4 \\
\hline Narrative ability & 7.5 & 3.4 & 8.9 & 4.0 & 8.4 & 2.7 & 7.1 & 3.1 & 5.6 & 2.7 \\
\hline PPVT-IIIB & 83.5 & 17.0 & 96.3 & 11.6 & 93.2 & 8.1 & 76.4 & 13.1 & 68.1 & 13.4 \\
\hline
\end{tabular}

*English L1 learners - no additional intervention.

${ }^{\dagger}$ ELLs - no additional intervention.

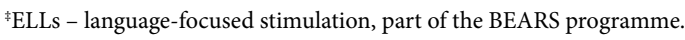

${ }^{\varsigma}$ ELLs - comprehensive literacy stimulation (i.e. complete BEARS programme).

have significantly better mean scores than the ELLs in groups 3 and 4 on the following subtests: word definitions (group 4, $p<0.001$ ), narrative ability (group $3, p<0.05$; group $4, p<0.001$ ) and the PPVT-IIIB (groups 3 and $4, p<0.001$ ). As these three subtests are sensitive to receptive and expressive language proficiency, these group differences support the conclusions of previous studies that ELLs might exhibit a language delay with regard to grammatical and especially vocabulary development (Catts et al., 2001; Genesee et al., 2004). The evidence for vocabulary delay is more compelling than the case for grammatical delay; Genesee et al. (2004) highlight the heterogeneity of the ELL population and the impact that different degrees, contexts and quality of exposure to the language have on language development. It could be that vocabulary development correlates more closely with characteristics of the input to which ELLs are exposed than syntactic and morphological development. Rosin (in Justice, 2006a) comments on the difficulty researchers experience in controlling for variability in bilingualism and therefore, by implication, for variability in English language proficiency of ELLs. The heterogeneity of the ELL population became apparent in the current study, providing support for Rosin's comment. ELLs in group 2 (the ELL control group) performed significantly better than their ELL peers in groups 3 and 4 (the two experimental groups) on two subtests, namely word definitions (group $3, p<0.01$; group $4, p<0.001$ ) and the PPVT-IIIB (group $4, p<0.001$ ). Moreover, ELLs in group 2 performed significantly better than their ELL peers $(p<0.01)$ as well as their English L1 peers $(p<0.001)$ on the subtest of rhyme production. Furthermore, the pre-intervention results of this study highlight the considerable variation in performance of L2 learners, and the fact that some L2 learners exhibit similar emergent literacy skills than their L1 peers, at times even outperforming them, without intervention and before entering grade 1 .
The second research question pertained to the emergent literacy skills of the ELLs after the intervention period. Table IV shows the performance of participants, first combined and then per group, on the eight ELA subtests administered post-intervention, i.e. 4 months after the initial assessment.

ANOVA was conducted post-intervention and indicated significant differences between the four groups on all eight subtests. The ANOVA and post-hoc Bonferroni multiple comparison results are summarised in Table V.

Whereas English L1 learners (group 1) before intervention outperformed their ELL peers in the two experimental groups (groups 3 and 4) on measures of language ability only, Table $\mathrm{V}$ indicates that, in addition to performance in the three language-related subtests, group 1 also performed significantly better post intervention than did groups 3 and 4 on the sounds-in-words and concepts of print subtests, respectively. Furthermore, in comparison with results from the initial assessment, group 2 (the ELL control group) performed significantly better than their L2 peers in the experimental groups on three additional subtests upon entering grade 1, namely rhyme recognition, concepts of print and letter recognition.

In order to determine whether any of these observed differences in performance over the 4 months were brought about by the respective stimulation programmes in the experimental classrooms or by the curricula followed in the control classrooms, repeated measures ANOVA was employed for the two main effects, namely time and intervention (time ${ }^{\star}$ intervention). A significant difference for the interaction between the two main effects was present on one subtest, 
Table V. Significant differences in performance on ELA subtests post intervention $\left(p<0.05^{*}, p<0.01^{\dagger}, p<0.001^{*}\right)$

$\begin{array}{llll}\text { ELA subtest } & \text { F (3.65) } & \boldsymbol{p} & \text { Post-hoc results } \\ \text { Sounds-in-words } & 4.3 & 0.008^{\dagger} & \text { Group 1 performed better than group 3 } \\ \text { Rhyme recognition } & 5.2 & 0.003^{\dagger} & \text { Group 2 performed better than groups 3 and } 4 \\ \text { Rhyme production } & 5.2 & 0.003^{\dagger} & \text { Group 2 performed better than groups 3 and } 4 \\ \text { Letter recognition } & 6.2 & 0.001^{\dagger} & \text { Group 2 performed better than groups } 3 \text { and } 4 \\ \text { Concepts about print } & 5.1 & 0.003^{\dagger} & \text { Groups 1 and 2 performed better than group } 4 \\ \text { Word definitions } & 11.5 & 0.000^{\ddagger} & \text { Group 1 performed better than groups 3 and 4, and group 2 performed better than group 4 } \\ \text { Narratives } & 4.1 & 0.010^{*} & \text { Group 1 performed better than group } 4 \\ \text { PPVT-IIIB } & 21.1 & 0.000^{\ddagger} & \text { Groups 1 and 2 performed better than groups 3 and } 4\end{array}$

the letter recognition subtest, indicating that the observed difference in pre- and post-intervention scores for this subtest can be attributed to intervention effect as opposed to normal developmental changes.

L1 learners and ELLs in the control group (groups 1 and 2) made significant progress with regard to alphabet letter knowledge over the 4-month period prior to entering grade 1 . In relation to their peers, the two experimental groups on the other hand did not make any significant progress on this emergent literacy skill, despite having received additional intervention. Possible explanations for this include:

1. The content of the curriculum followed and/or teacher-specific emphasis on alphabet letters in the two control classrooms contributed to the observed improvement in alphabet knowledge of learners in groups 1 and 2. Learners in both these control groups were exposed to the Letterland programme (Wendon, 2003) which makes explicit use of letter-sound associations. Some, but not all, learners in groups 3 and 4 were also exposed to the Letterland programme as part of their normal class curriculum.

2. The amount of time and depth dedicated to alphabet letter knowledge in the BEARS stimulation programme was not sufficient to bring about significant improvement for ELLs in the experimental groups.

3. Where learners are also lagging behind in other areas of language development, a 4-month period is not sufficient for ELLs to consolidate this particular subskill. This conclusion is supported by the fact that group 2 had already performed significantly better than their L2 peers on two language-related subtests pre-intervention (word definitions and the PPVT-IIIB), which might indicate that they were better equipped to integrate and consolidate skills pertaining to alphabet knowledge.

4. Learners in group 4, who received the comprehensive BEARS programme and were expected to show progress in this subskill, consistently scored lower than their peers in the ELL control group on the language-related subtests, namely word definitions, narrative ability and the PPVT-IIIB. On the PPVT-IIIB, this group scored more than two standard deviations below the mean, indicating extremely delayed receptive vocabulary abilities. The group's ability to understand instructions and process procedural literacy knowledge might have been restricted by the observed language delay in relation to their ELL peers.

In order to further investigate the observed performance of the English L2 control group (group 2) in relation to that of the two intervention groups, three possible confounding variables that could have resulted in the observed differences in performance were considered, namely SES, characteristics of the learners' L1, and effect of curriculum or teacher characteristics. Each will be discussed below.

\section{Socio-economic status}

For the purpose of determining the possible confounding effect of SES, L1 learners were not included in the analysis of data, in order to eliminate the influence of home language on test results. Fourteen
ELLs were categorised in the low-SES group, while 36 learners were in the high-SES group. In line with previous studies on the effect of SES on literacy measures (Dodd \& Carr, 2003; Duncan \& Seymour, 2000), the ELLs performed as one would predict: participants in the low-SES group scored consistently lower than participants in the high-SES group across the eight ELA subtests, both before and post intervention. ANOVA was conducted to assess the impact of SES on learners' performance on the ELA over the 4-month intervention period. There was no significant interaction between time and SES for any of the eight subtests, confirming that while learners in the high SES group $(n=36)$ both before and post intervention had higher mean scores than their peers from more disadvantaged backgrounds $(n=14)$, this gap neither widened nor narrowed significantly over the 4 -month period prior to entering grade 1.

A substantial main effect for SES indicated that learners with high SES performed significantly better than their peers from disadvantaged backgrounds on the three language-related subtests: word definitions: $\mathrm{F}(1.48)=7.9, p<0.01$; narratives: $\mathrm{F}(1,48)=6.8, p<0.05$; and the PPVTIIIB: $\mathrm{F}(1.48)=10.6 ; p<0.01$. This result corroborates studies which found that language skill varies systematically as a function of SES (Duncan \& Seymour, 2000; Hoff, 2006). In an attempt to explain this phenomenon, Hart and Risley (1995) found that mothers with higher SES talked more, used a richer vocabulary and provided more information about objects being labelled than did mothers from a more disadvantaged socio-economic background.

\section{Characteristics of learners' $\mathrm{L} 1$}

Repeated measures ANOVA were conducted to assess the possible influence of $\mathrm{L} 1$ on performance over the 4 months of intervention. The results of this analysis showed that there was no significant interaction between language and time (time*language), indicating that no language group (Afrikaans L1, English L1, isiXhosa L1 or other L1) performed significantly different to any of the other groups over the 4 -month period prior to entering grade 1 .

\section{Effect of curriculum or teacher characteristics}

There was no significant interaction between time and teacher (time ${ }^{\star}$ teacher) on any of the eight subtests, indicating that teacherspecific characteristics or the specific curriculum followed in addition to the BEARS stimulation programme did not influence these learners' performance on the ELA over the 4-month intervention period. There was, however, a significant teacher effect on three language-related subtests, namely word definitions, fictional narratives and the PPVTIIIB, with ELLs in the classroom of teacher e performing significantly poorer than their ELL peers in the other experimental classrooms. While several variables could have contributed to the performance of teacher e's learners, the combination of this teacher's L1 (Afrikaans), her considerably shorter teaching experience and the high percentage of ELLs in her classroom (impacting on peer learning opportunities) seems to offer a plausible explanation for her learners' poor performance.

\section{Conclusions}

The performance of the ELL control group highlighted the heterogeneity of the ELL population with regard to their emergent literacy abilities. While the BEARS programme was developmental in nature, aiming 
at providing a population at risk for reading difficulties with critical subskills to close the gap between them and their English L1 peers over a short period, it is clear that the growth trajectory of ELLs should be monitored very carefully over an extended period by means of culturally and linguistically valid assessment measures. As stated by Hus (2001), a vast number of research findings confirm that in the population of children with significant reading problems, there is a disproportionate representation of children who come from poor, racial minority or cultural minority ${ }^{\dagger}$ groups and are L1 speakers of languages other than English. While the present study indicated that ELL status in isolation does not necessarily result in delayed emergent literacy skills (cf. the performance of group 2, for instance), the combination of being an ELL, coming from a disadvantaged background, being in a classroom with a high percentage of ELLs and having a teacher with limited experience with this population might have a compounded impact on these learners' emergent literacy skills, in particular their oral language skills. For ELLs, a group with observed variability in receptive and expressive language abilities, teachers' language use is even more important and thus warrants definite attention and focus as part of an emergent literacy intervention programme. Dickinson and Sprague (2002) conclude that providing high-quality further professional development opportunities to teachers is of critical importance. They have found two aspects of teachers' conversations to be associated with end of kindergarten (grade $\mathrm{R}$ ) assessment results, namely their use of rare and unfamiliar words and their ability to limit how much they said and hence to listen to what children were saying. Weitzman and Greenberg (2002) concurred with the importance of these two aspects which often warrant intensive training and specific guidance to teachers on how to adapt their language use to facilitate ELLs' receptive and expressive language development. In this regard, the SLT needs to fulfil a consultative role and be proactive with regard to early appropriate assessment and intervention for learners who lag behind their peers.

With regard to the development and implementation of emergent literacy intervention programmes, the content, timing and predictive value of skills need careful consideration. Although the BEARS programme was based on evidence-based principles and incorporated oral language, print awareness and phonological awareness components, learners did not show any significant improvement in relation to two control groups who followed a commercially available phonics programme. While ELL participants in the experimental groups showed significant improvement in several subskills over the 4 -month period, they did not close the gap between themselves and their L1 peers, or between themselves and an ELL control group with age-appropriate language skills. However, when participants were matched with regard to receptive language pre-intervention, there was no significant difference in performance upon entering grade 1 , suggesting that the area of oral language needs to be reconsidered in the development of emergent literacy programmes. A more explicit approach towards semantic and syntactic language development within the literacy curriculum for ELLs should be explored and evaluated (Fey, Cleave, Long \& Hughes, 1993; Justice, Mashburn, Pence \& Wiggins, 2008). In other words, what is often referred to as 'general language stimulation' (which usually involves reading stories and teaching vocabulary based on certain semantic themes) might not suffice for ELLs. Rather, ELLs should be exposed to more specific scenarios which will give them the opportunity to acquire certain complex syntactic structures and also vocabulary items other than nouns, verbs, adjectives and adverbs (i.e. to also acquire, for example, quantifiers and conjunctions).

Finally, the results of this study call for researchers, clinicians and educators to be more rigorous in their approach to early literacy assessment and intervention, more accountable in their objective measuring of outcomes and more flexible in making the necessary changes when it becomes apparent that a particular approach is not

${ }^{\dagger}$ Hus (2001) refers to racial minorities in the USA and Canadian context, whereas the situation in the current study in South African English classrooms involves children from a racial majority who voluntarily choose to receive their education in English, their L2 or additional language. providing optimal results. While there is still a paucity of scientific evidence for effective emergent literacy intervention programmes for learners educated in their L2, Justice and Pence (2004) recommend that practitioners integrate existing evidence with theoretical, practical and personal knowledge and continue to do so in the best interest of the ELL population we serve.

\section{Acknowledgement}

This material is based on work financially supported by The National Research Foundation (NRF) and Western Cape Language Committee (WCLC). Any opinions, findings, conclusions or recommendations expressed in this material are those of the authors and not of the NRF and WCLC.

\section{References}

Anthonissen, C. (2009). Bilingualism and language shift in Western Cape communities. Stellenbosch Papers in Linguistics PLUS (special issue on multilingualism and language policies in Africa), 38, 61-76.

Bennett-Armistead, V. S., Duke, N. K., \& Moses, A. M. (2005). Literacy and the youngest learner. New York: Scholastic.

Bialystok, E. (2001). Bilingualism in development: language, literacy and cognition. Cambridge: Cambridge University Press.

Bird, J., Bishop, D. V. M., \& Freeman, N. (1995). Phonological awareness and literacy development in children with expressive phonological impairments. Journal of Speech and Hearing Research, 38, 446-462.

Boudreau, D. M., \& Hedberg, N. L. (1999). A comparison of early literacy skills in children with specific language impairment and typically developing peers. American Journal of Speech Language Pathology, 8, 248-263.

Bradley, L., \& Bryant, P. E. (1983). Categorizing sounds and learning to read: a causal connection. Nature, 301, 419-421.

Catts, H. W., Fey, M. E., Zhang, X., \& Tomblin, J. B. (2001). Estimating the risk of future reading difficulties in kindergarten children: A research-based model and its clinical implementation. Language, Speech and Hearing Services in Schools, 32(1), 38-48.

Cavanaugh, C. L., Kim, A., Wanzek, J., \& Vaughn, S. (2004). Kindergarten reading interventions for at-risk students: Twenty years of research. Learning Disabilities: A Contemporary Journal, 2(1), 9-21.

Clay, M. (1979). The early detection of reading difficulties. (2nd ed.). Auckland, NZ. Heinemann.

Clay, M. (2000). Follow me, Moon. Portsmouth, NH: Heinemann.

Dickinson, D. K., \& Sprague, K. E. (2002). The nature and impact of early childhood care environments on the language and early literacy development of children from lowincome families. In S. B. Neuman \& D. K. Dickinson (Eds.), (2002). Handbook of early literacy research. New York: Guilford Press.

Dodd, B., \& Carr, A. (2003). Young children's letter-sound knowledge. Language, Speech and Hearing Services in Schools, 34, 128-137.

Duncan, L. G., \& Seymour, P. H. K. (2000). Socio-economic differences in foundation-level literacy. British Journal of Psychology, 91, 145-166.

Dunn, L. M., \& Dunn, L. M. (1997). Peabody picture vocabulary test (3rd ed.). Circle Pines, MN: American Guidance Service.

Du Plessis, E. (2003). A conceptual framework for accelerating emergent literacy skills of disadvantaged pre-schoolers. Dissertation Abstracts International, 63(10), 3516-A.

Fey, M. E., Cleave, P. L., Long, S. H., \& Hughes, D. L. (1993). Two approaches to the facilitation of grammar in children with language impairment: An experimental evaluation. Journal of Speech and Hearing Research, 36(1), 141-152.

Genesee, F., Paradis, J., \& Crago, M. B. (2004). Dual language development and disorders. Baltimore: Paul H. Brookes.

Goswami, U., \& Bryant, P. E. (1990). Phonological skills and learning to read. Hove Psychology Press.

Hart, B., \& Risley, T. R. (1995). Meaningful differences in the everyday experiences of young American children. Baltimore: Brookes.

Hoff, E. (2006). Environmental supports for language acquisition. In D. K. Dickinson \& S. B. Neuman (Eds.), Handbook of early literacy research (Vol. 2, pp. 163-172). New York: Guilford Press.

Hulme, C., Hatcher, P. J., Nation, K., Brown, A., Adams, J., \& Stuart, G. (2002). Phoneme awareness is a better predictor of early reading skill than onset-rime awareness. Journal of Experimental Child Psychology, 82, 2-28.

Hus, Y. (2001). Early reading for low SES minority language children: An attempt to catch them before they fall. Folia Phoniatrica et Logopaedica, 53(3), 115-184.

Justice, L. M. (Ed). (2006a). Clinical approaches to emergent literacy intervention. San Diego: Plural Publishing.

Justice, L. M. (2006b). Evidence-based practice, response to intervention, and the prevention of reading difficulties. Language, Speech and Hearing Services in Schools, 37(4), 284-297.

Justice, L. M., Mashburn, A., Pence, K. L., \& Wiggins, A. (2008). Experimental evaluation of a preschool language curriculum: influence on children's expressive language skills. Journal of Speech, Language and Hearing Research, 51, 983-997.

Justice, L. M., \& Pence, K. (2004). Addressing the language and literacy needs of vulnerable children: Innovative strategies in the context of evidence-based practice. Communication Disorders Quarterly, 25, 173-178. 
Kaderavek, J. N., \& Justice, L. M. (2004). Embedded-explicit emergent literacy intervention II: Goal selection and implementation in the early childhood classroom. Language, Speech and Hearing Services in Schools, 35(3), 212-228.

Lipka, O., \& Siegel, L. S. (2007). The development of reading skills in children with English as a second language. Scientific Studies of Reading, 11(2), 105-131.

MacWhinney, B., \& Snow, C. (1995). The CHILDES Project: Tools for analyzing talk. NJ: Lawrence Erlbaum.

McGee, L. M., \& Richgels, D. J. (2003). Designing early literacy programs: Strategies for at-risk preschool and kindergarten children. New York: Guilford Press.

Moore, S. M., Pérez-Méndez, C., \& Boerger, K. (2006). Meeting the needs of culturally and linguistically diverse families in early language and literacy intervention. In L. M. Justice (Ed.), Clinical approaches to emergent literacy intervention (pp. 29-70). New York: Guilford Press.

Morrow, L. M. (2007). Developing literacy in preschool. New York: Guilford Press.

Müller, N. (2003). Multilingual communication disorders: exempla et desiderata. Journal of Multilingual Communication Disorders, 1, 1-12.

Nancollis, A., Lawrie, B., \& Dodd, B. (2005). Phonological awareness intervention and the acquisition of literacy skills in children from deprived social backgrounds. Language, Speech and Hearing Services in Schools, 36(4), 325-335.

Olivier, J. M. (2009). Investigating literacy development among learners with a second language as medium of instruction. Unpublished doctoral thesis: Department of General Linguistics, Stellenbosch University.

Paul, R. (2007). Language disorders from infancy through adolescence. (3rd ed.). St Louis: Mosby Elsevier.

Snow, C., Tabors, P., Nicholson, P., \& Kurland, B. (1995). SHELL: Oral language correlates and early literacy skills in kindergarten and first grade children. Journal of Research in Education, 10(1), 37-48.

SPSS Statistical software package. (2007). Microsoft: Version 15.

Stackhouse, J., \& Wells, B. (1997). Children's speech and literacy difficulties: A psycholinguistic framework (Book 1). London: Whurr.

StatSoft Inc. (2007). STATISTICA (data analysis software system). Version 8.0. USA: Statsoft Inc.

Vaughn, S., Linan-Thompson, S., \& Hickman, P. (2003). Response to instruction as a means of identifying students with reading/learning disabilities. Exceptional Children, 69, 391-409.

Weitzman, E., \& Greenberg, J. (2002). Learning language and loving it: A guide to promoting children's social, language and literacy development in early childhood settings (2nd ed.). Toronto: The Hanen Centre.

Wendon, L. (2003). Letterland ABC. Retrieved on 14 January 2006 from http://www.letterland. co.za/index.php

Weschler, D. (1974). Weschler Intelligence Scale for Children-Revised. New York: The Psychological Corporation.

Western Cape Education Department. Western Cape Language Policy. 2002. Retrieved on 24 February 2007 from http://wced.school.za/documents/lang_policy/index_exsum.html

Whitehurst, G. J., \& Lonigan, C. (2002). Emergent literacy: Development from prereaders to readers. In S. B. Neuman \& D. K. Dickinson (Eds.), Handbook of early literacy research (pp. 11-29). New York: Guilford Press.

Willenberg, I. A. (2004). Getting set for reading in the rainbow nation: Emergent literacy skills and literacy environments of children in South Africa. Unpublished doctoral thesis: Faculty of the Graduate School of Education, Harvard University: ProQuest Information and Learning Company.

\section{Appendix A: Content and scoring procedures of the emergent literacy assessment}

\section{Subtest}

Sounds-in-words

Rhyme recognition

Rhyme production

Word definitions

Concepts about print

Letter recognition

Fictional narrative

Peabody picture

vocabulary test

\section{Description}

A phoneme matching task in which children were expected to match two (out of three) words that had either the same initial or the same final phonemes. Picture cues were provided in order to minimise the effect of auditory memory. Example: cat - ball - bag

Children were expected to identify two (out of three) words that rhymed. Picture cues were provided in order to minimise the effect of auditory memory. Example: cat - hat - ring

A rhyming pair was provided, and children were required to provide another rhyming word. No picture cues were provided.

This subtest was based on the word definition subtest of the Weschler intelligence scale for children (WISC-R; Weschler 1974) and required children to define 13 (assumedly) familiar nouns: alphabet, bicycle, bird, clock, diamond, donkey, flower, foot, hat, knife, nail, thief and umbrella. No picture cues were provided.

This subtest was based on the original concepts about print test (Clay, 1979) and utilised Clay's (2000) book Follow me, moon as stimulus. Concepts such as the front and back of the book, print direction and orientation, and literacy related terminology such as word, letter or page were assessed.

Children were provided with two alphabet charts with upper or lower case letters randomly displayed and they were expected to name all the letter names they knew.

The Bear Story (Snow, Tabors, Nicholson \& Kurland, 1995), made up of three colour pictures, was presented and children were expected to formulate a narrative based on these pictures.

The PPVTIII-B (Dunn \& Dunn, 1997) - a standardised, norm-referenced assessment of receptive vocabulary - was administered.

\section{Scoring procedure}

Each correct response was credited with one point.

Each correct response was credited with one point

Each correct response was credited with one point

Responses were directly transcribed and audiorecorded. Transcriptions were checked against the recordings and then coded according to the CHAT system (codes for the human analysis of transcripts; MacWhinney \& Snow, 1995). Definitions were coded for structure and content. Six points were awarded for super-ordinates (\$SUPO), two or four points for functional actions ( $\$ F U N$ ) or definitional features (\$DFT) and one point each for examples, descriptions, associations and applications (\$EDAA) Scores were summated to create a total word definition score.

Each correct response was credited with one point.

Each correct response was credited with one point Each letter of the alphabet was only credited once.

Narratives were directly transcribed and audiorecorded so that the transcription could be verified later. After verification, coding was done according to the CHAT system. Story-structure features, content, written-discourse features and micro-linguistic features were analysed. One point was assigned for each feature, and points were summated to create a total bear story score.

Scoring was done according to the instructions of this formal assessment procedure. 